\title{
Varicose Vessels Within Pulmonary Metastasis of Giant Cell Tumor: Unusual Radiological Manifestation
}

\author{
Sara Haseli ${ }^{1}$, Siamak Malekpour ${ }^{1}$ and Seyed Hamed Jafari ${ }^{1,{ }^{*}}$ \\ ${ }^{1}$ Department of Radiology, Medical Imaging Research Center, Shiraz University of Medical Sciences, Shiraz, Iran \\ Corresponding author: Seyed Hamed Jafari, Department of Radiology, Medical Imaging Research Center, Shiraz University of Medical Sciences, Namazi Hospital, Zand Ave, \\ Shiraz, Iran. Tel: +98-9173138381, Fax: +98-7136302442, E-mail: hamed338@yahoo.com
}

Received 2017 November 19; Revised 2017 December 12; Accepted 2018 February 21.

\begin{abstract}
Giant cell tumor (GCT) is one of the most common benign bone tumors that can metastase to distant organs such as lungs as the most common site; however, pulmonary metastasis does not mean poor prognosis. We report a case of lung metastasis of giant cell tumor with varicose vessels within them, which is an extremely rare radiological appearance. Varicose vessels within these metastases have the same radiologic appearance resembling arteriovenous malformation (AVM), and if diagnosed inaccurately it can affect patient management significantly. As these varicose vessels have a potential risk of bleeding during biopsy or even spontaneously that can lead to hemothorax, we recommend contrast enhanced computed tomography scan (CT scan) after detecting lung metastasis in patients with giant cell tumor. We report here a case of varicose vessels within lung metastasis of giant cell tumor, which is a rare radiologic manifestation.
\end{abstract}

Keywords: Giant Cell Tumor, Pulmonary Metastasis, Varicose Vessels

\section{Introduction}

Giant cell tumor accounts for $5 \%-10 \%$ of all primary bone neoplasms. It can be locally aggressive or even metastase to distant organs such as the lungs as the most common site (1). However, its metastasis does not mean poor prognosis and metastatectomy is a way to cure these patients (1).

In our presented case, computed tomography scan (CT scan) showed varicose vessels within multiple lung metastases a rare radiologic feature. To the best of our knowledge, only one case of such manifestation has been reported (2).

\section{Case Presentation}

A 19-year-old female was diagnosed with giant cell tumor of the patella two years ago after severe right knee pain. She had no fever or weight loss. Her family history was negative for bone tumors. Physical examination was unremarkable except for tenderness over the right patella. Her initial X-ray of the right knee showed a lytic lesion with a narrow zone of transition and non-sclerotic border in the right patella. The overlying cortex was thinned but not eroded and no mineral calcification was found. There was also evidence of pathologic fracture within it (Figure 1). Surgical resection was performed. Histopathological examination confirmed giant cell tumor of the patella (Figure 2). She was on her routine follow up until one month prior to admission when she developed progressive dyspnea. Initial chest x-ray showed multiple varying size opacities in both lung fields with left sided pleural effusion (Figure 3).

Multiple lung masses were revealed with engorged varicose vessels in contrast enhanced CT scan (Figure 4). Next, biopsy under the guide of CT scan was done, which revealed metastatic giant cell tumor (Figure 5). Knee MRI was performed, which revealed no local recurrence. Finally, she underwent exploratory thoracotomy with pneumolysis and metastatectomy, resection of masses was performed on the left side, and the future plan was to do the same thing on the right side.

\section{Discussion}

Giant cell tumor is a benign bone tumor that accounts for $20 \%$ of all benign bone tumors. Its female/male ratio is 1.5:1, and most cases are 20 - 40 years old. The most common giant cell tumor (GCT) site is around the knee in the 

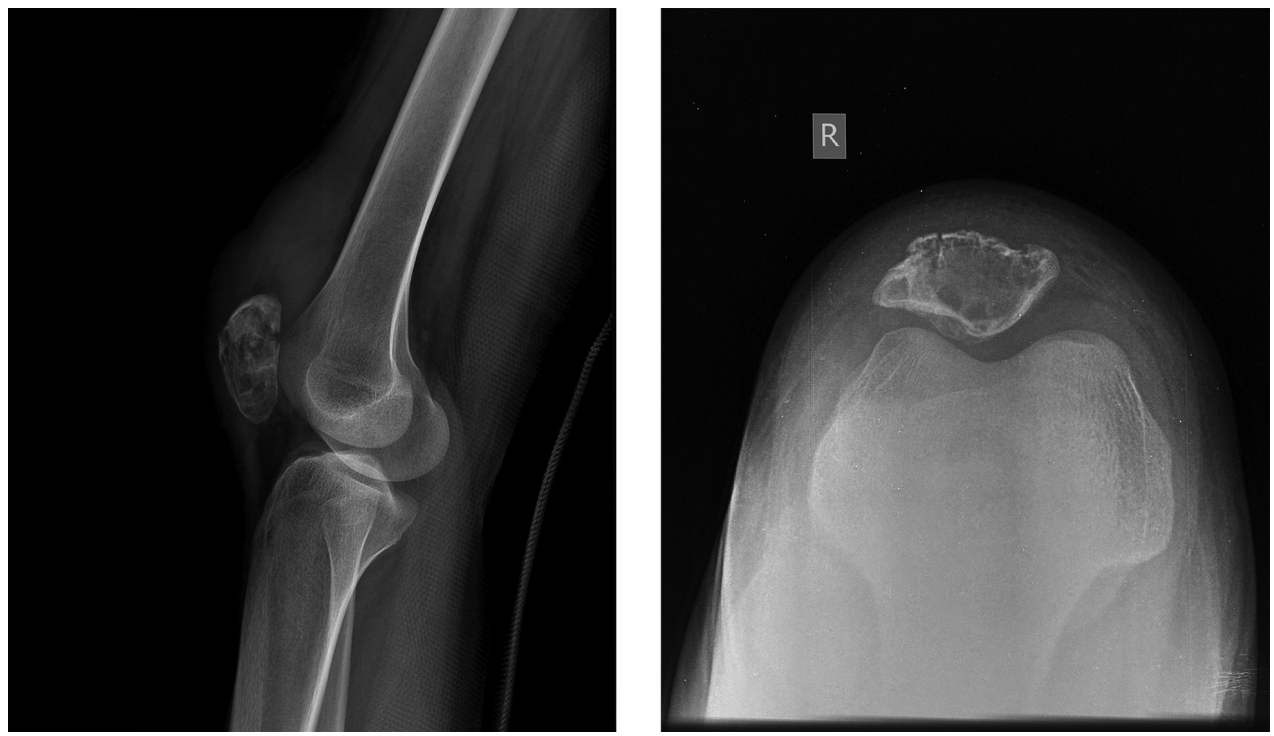

Figure 1. A 19-year-old female with a history of giant cell tumor of the patella. Lateral and patellar views of knee X-ray demonstrate a lytic lesion with narrow zone of transition and non-sclerotic border in the right patella. The overlying cortex is thinned but not eroded and no mineral calcification is found. Evidence of pathologic fracture is also noted.

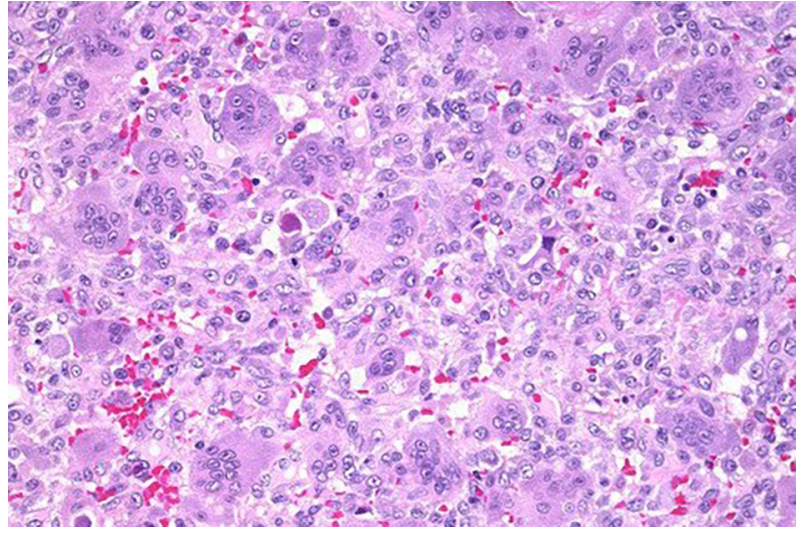

Figure 2. Histopathological evaluation of the patellar lesion. Microscopic section shows distributed gaint cells with mononuclear cells in between ( $\mathrm{H} \& \mathrm{E}$ staining, $\times$ 100).

distal femur, proximal of tibia and distal radius $(1,3)$. Typical GCT is an eccentrically located lytic lesion with nonsclerotic border in long bones with sub articular extension (1). Patella is an unusual location of bone neoplasm. Radiologic features essentially cannot differentiate benign from malignant patellar neoplasm. However, the majority of its neoplasms are benign and giant cell tumor accounts for $33 \%$ of all patellar tumors (4). Usual clinical presentation of patellar GCT is knee pain with or without swelling (5).

In spite of GCT benign features, it can be locally aggres-

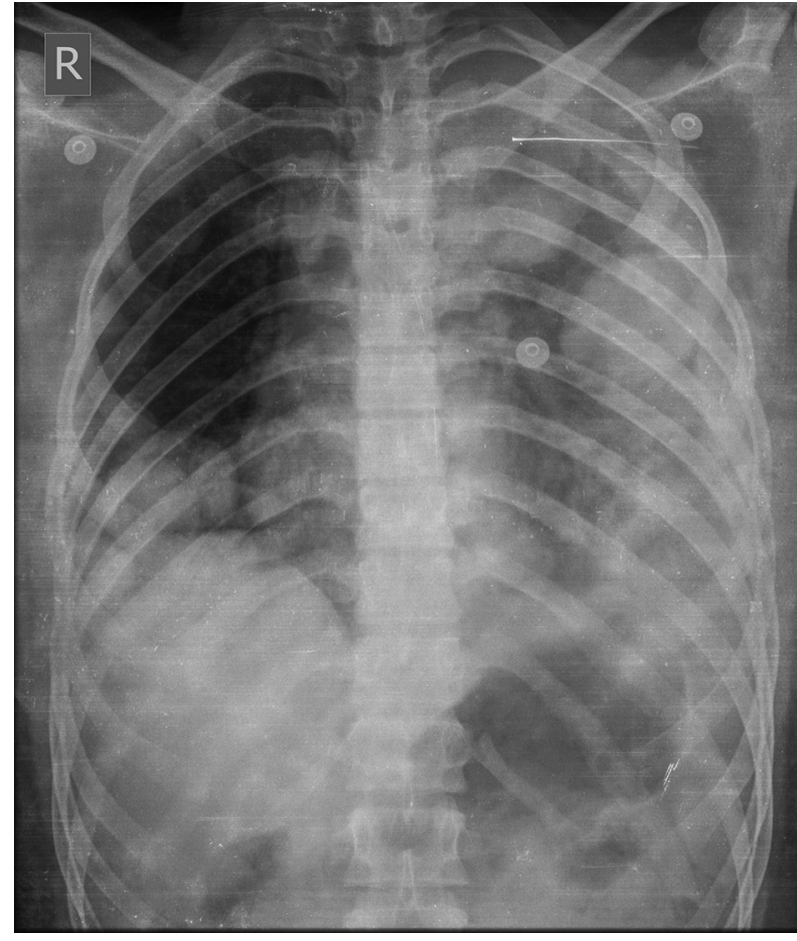

Figure 3. Frontal view of chest radiography reveals multiple varying size masses in both lung fields with left sided pleural effusion 

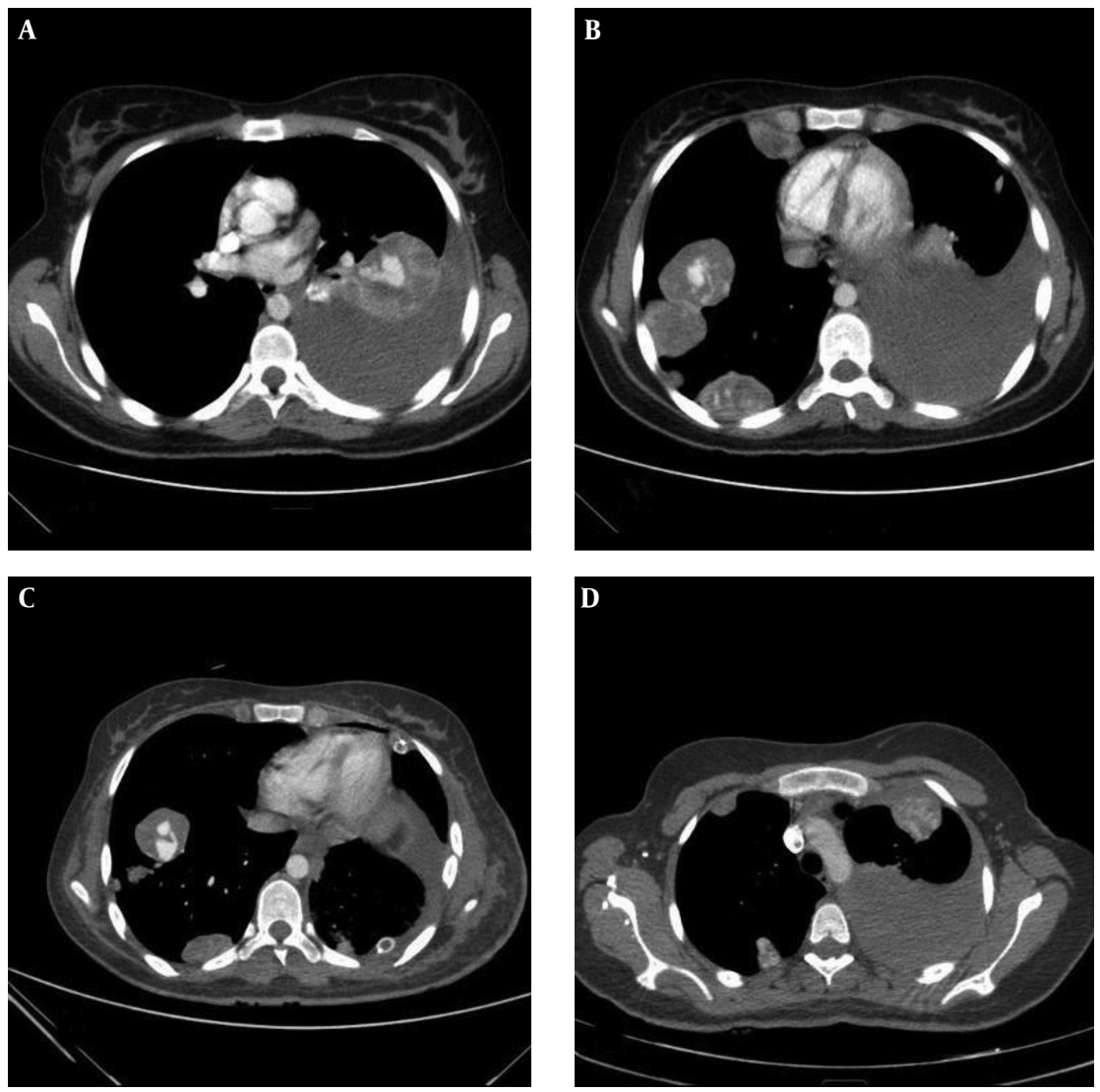

Figure 4. A - D, Contrast enhanced CT scan shows multiple masses with varicose vessels within them with left sided pleural effusion.
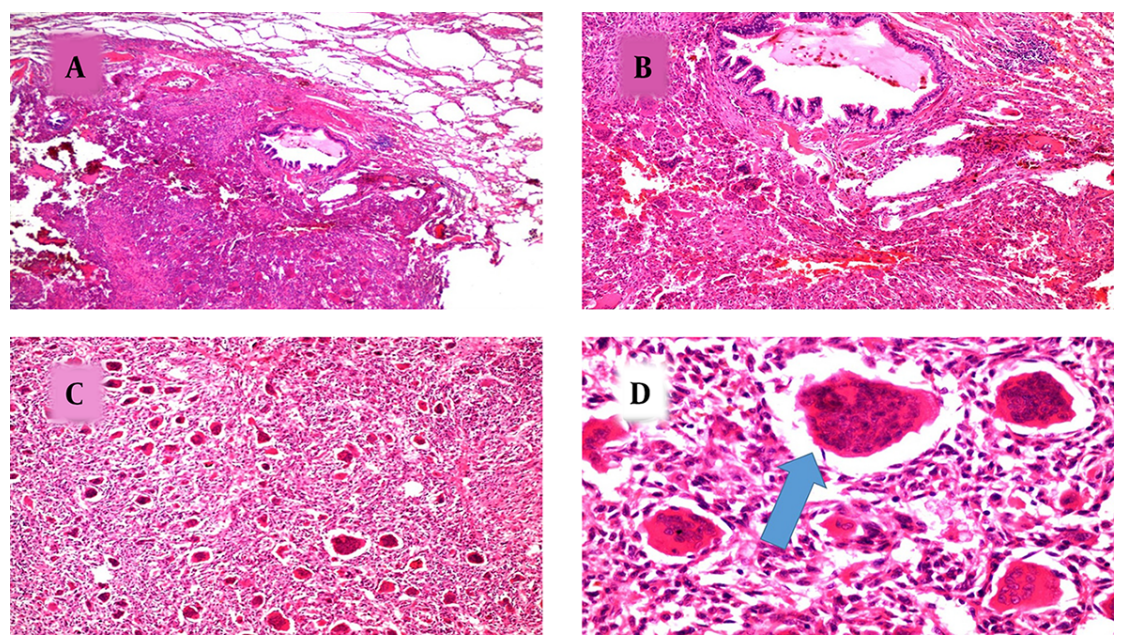

Figure 5. Histopathological evaluation of the lung nodule. A and B, Microscopic section shows normal lung parenchyma involved by tumoral process in the lower part of the slide (H \& E staining, $\times 40, \times 100)$. C and D, Sections show evenly distributed giant cells (arrow) in the background of mononuclear cells. $(\mathrm{H} \& \mathrm{E}$ staining, $\times 100, \times 400)$.

sive or even metastase to soft tissues, liver, brain, and lung (1). $15 \%-25 \%$ of patients present with local recurrence af- ter initial treatment (5). Lung metastasis occurs in $1-6 \%$ of cases that occur within ten years, with the mean time of 3.5 
years after the initial treatment either with or without local recurrence (6).

Lung is the most common site for giant cell tumor metastasis and occurs more probably in patients with a history of local recurrence or radiologically aggressive appearance of primary tumor (7). Both giant cell tumor and its pulmonary metastasis are benign and there is no correlation between the location of giant cell tumor and the risk of lung metastasis (8).

Due to successful treatment of giant cell tumor lung metastasis and the rare occurrence of it, wide surgical resection of primary tumor in order to prevent further metastasis is not recommended (3).

Radiologic features of lung metastasis include solitary or multiple homogeneous lesions. These masses usually have a narrow zone of transition with lung parenchyma and are predominately located in basal segments and periphery regions of the lungs (6). Hence, masses with feeding vessels and varicosity are extremely rare. Varicose vessels within pulmonary masses are also infrequent with only few cases ever been reported with possible mechanism of angiogenic factor created by masses $(2,9)$. In addition, varicose vessels within these metastases have the same radiologic appearance resembling arteriovenous malformation (AVM) (2). If diagnosed inaccurately, it can affect patient management significantly.

In non-contrast enhanced CT scan, these are homogeneous masses, and contrast enhanced CT scan is essential to show its feeding artery and draining veins (2). As these varicose vessels have the potential risk of bleeding during biopsy or even spontaneously that can lead to hemotho$\operatorname{rax}(2)$, we recommend contrast enhanced CT scan after detecting lung metastasis in patients with giant cell tumor. Therefore, after treatment close follow up is necessary in order to have a proper diagnosis and management.

\section{Acknowledgments}

We would like to thank Dr. Dehghanian for his assistance with the pathology report, and Dr. Saki for her valuable comments that greatly improved this manuscript.
The authors wish to thank Mr. Argasi at the research consultation center (RCC) at Shiraz University of Medical Sciences for his invaluable assistance in editing this manuscript.

\section{Footnotes}

Authors' Contributions: None declared. Financial Disclosure: None declared. Funding/Support: None declared.

\section{References}

1. Chakarun CJ, Forrester DM, Gottsegen CJ, Patel DB, White EA, Matcuk GR Jr. Giant cell tumor of bone: review, mimics, and new developments in treatment. Radiographics. 2013;33(1):197-211. doi: 10.1148/rg.331125089. [PubMed: 23322837].

2. Yeo CD, Roh SY, Shin OR, Bahk WJ, Kim KH, Kim JW. A case of pulmonary metastasis of giant cell tumor of bone presenting as pulmonary arteriovenous malformation. J Formos Med Assoc. 2015;114(4):369-72. doi: 10.1016/j.jfma.2012.03.014. [PubMed: 25839772].

3. Muheremu A, Niu X. Pulmonary metastasis of giant cell tumor of bones. World J Surg Oncol. 2014;12:261. doi: 10.1186/1477-7819-12-261. [PubMed: 25139054]. [PubMed Central: PMC4155080].

4. Song M, Zhang Z, Wu Y, Ma K, Lu M. Primary tumors of the patella. World J Surg Oncol. 2015;13:163. doi: 10.1186/s12957-015-0573-y. [PubMed: 25906772]. [PubMed Central: PMC4435649].

5. Shibata T, Nishio J, Matsunaga T, Aoki M, Iwasaki H, Naito M. Giant cell tumor of the patella: An uncommon cause of anterior knee pain. Mol Clin Oncol. 2015;3(1):207-11. doi: 10.3892/mco.2014.433. [PubMed: 25469296]. [PubMed Central: PMC4251109].

6. Tubbs WS, Brown LR, Beabout JW, Rock MG, Unni KK. Benign giantcell tumor of bone with pulmonary metastases: clinical findings and radiologic appearance of metastases in 13 cases. AJR Am J Roentgenol. 1992;158(2):331-4. doi: 10.2214/ajr.158.2.1729794. [PubMed: 1729794].

7. Thiago Carneiro da Cunha B, Fernando Coelho Goulart de A, Celso Montenegro T, Júnior Hélio Antonio R, Marcelo Cunha F, Etchebehere Renata Margarida E. Lung metastasis of benign giant cell tumor: a case report. Radiol Bras. 2008;41(3):207-9.

8. Chen CC, Liau CT, Chang CH, Hsu YH, Shih HN. Giant Cell Tumors of the Bone With Pulmonary Metastasis. Orthopedics. 2016;39(1):e68-73. doi: 10.3928/01477447-20151228-04. [PubMed: 26730686].

9. Challa R, Irion KL, Hochhegger B, Shackloth M, Elsayed H, Gosney JR, et al. Large pulmonary masses containing varicose veins: a rare presentation of benign metastasising leiomyomas. Br J Radiol. 2010;83(995):e243-6. doi: 10.1259/bjr/49938718. [PubMed: 20965897]. [PubMed Central: PMC3473723]. 